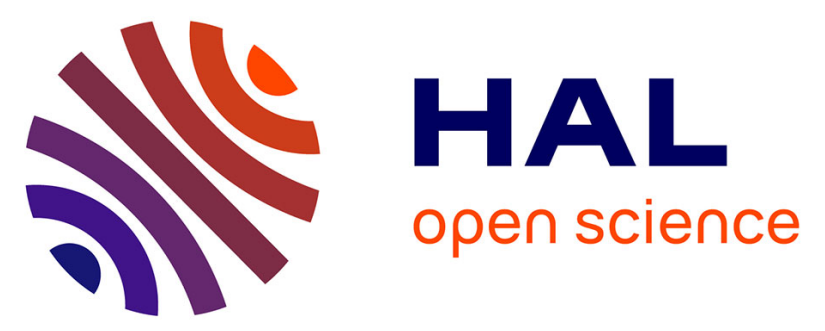

\title{
Comparison Between a Job-Exposure Matrix (JEM) Score and Self-Reported Exposures for Carrying Heavy Loads Over the Working Lifetime in the CONSTANCES Cohort
}

Laure Ngabirano, Marc Fadel, Annette Leclerc, Bradley Evanoff, Ann Marie

Dale, Yves Roquelaure, Alexis Descatha

\section{To cite this version:}

Laure Ngabirano, Marc Fadel, Annette Leclerc, Bradley Evanoff, Ann Marie Dale, et al.. Comparison Between a Job-Exposure Matrix (JEM) Score and Self-Reported Exposures for Carrying Heavy Loads Over the Working Lifetime in the CONSTANCES Cohort. Annals of Work Exposures and Health, 2020, 64 (4), pp.455-460. 10.1093/annweh/wxaa015 . hal-02495680

\section{HAL Id: hal-02495680 \\ https://univ-angers.hal.science/hal-02495680}

Submitted on 18 May 2020

HAL is a multi-disciplinary open access archive for the deposit and dissemination of scientific research documents, whether they are published or not. The documents may come from teaching and research institutions in France or abroad, or from public or private research centers.
L'archive ouverte pluridisciplinaire HAL, est destinée au dépôt et à la diffusion de documents scientifiques de niveau recherche, publiés ou non, émanant des établissements d'enseignement et de recherche français ou étrangers, des laboratoires publics ou privés. 
Comparison between a job-exposure matrix (JEM) score and self-reported exposures for carrying heavy loads over the working lifetime in the CONSTANCES cohort.

Laure Ngabirano ${ }^{1,2}$, Marc Fadel $^{2,3}$, Annette Leclerc ${ }^{2}$, Bradley A. Evanoff ${ }^{4}$, Ann Marie Dale ${ }^{4}$, Yves Roquelaure ${ }^{1}$, Alexis Descatha ${ }^{1,2,3}$

1. Univ Angers, CHU Angers, Univ Rennes, Inserm, EHESP, Irset (Institut de recherche en santé, environnement et travail) - UMR_S 1085, F-49000 Angers, France

2. Versailles St-Quentin Univ, Paris Sud Univ, Paris Saclay Univ, Inserm, UMR 1168 UMS011, Villejuif, France

3. AP-HP, UVSQ, IIMTPIF, Unité Hospitalo-Universitaire de Santé professionnelle Hôpitaux Universitaires de Paris Ile-de-France Ouest, site Raymond Poincaré, Garches, France

4. Division of General Medical Sciences, Washington University School of Medicine in St. Louis, St Louis, USA

Correspondence to: Laure Ngabirano, Inserm UMRS 1168, VIMA- Aging and chronic diseases - Epidemiological and public health approaches, 16 Avenue Paul Vaillant Couturier, 94807 Villejuif cedex, France; email: laure.ngabirano@inserm.fr

\section{What is new?}

A Job-Exposure Matrix based biomechanical exposure score, derived from self-reported data, agreed well with a simpler set of self-reported exposure values at the individual level. Area Under Curves for the score were satisfactory (0.795-0.826) for the exposure periods considered. This method allows assignment of recent and past exposures in large databases containing only job titles. 


\section{ABSTRACT}

Background. Job-exposure matrices (JEMs) were developed to allow assessment of past work exposure for large population-based studies where better exposures data are unavailable. Few studies have directly compared biomechanical JEMs to self-administered questionnaires. We compared assessments of cumulative exposure to carrying heavy loads based on "JEM Constances” to individually self-reported (SR) exposures.

Methods. In the French CONSTANCES cohort at inception, past SR exposure to carrying heavy loads (ever/never and durations) and a detailed job history were available for 26,929 subjects. JEM Constances, an existing biomechanical JEM based on self-reported current exposures from 26,821 asymptomatic workers, was combined with job history to build a cumulative biomechanical exposure score. Using individual SR exposure as the reference, Area Under the Curve (AUC) of Receiver Operating Characteristic (ROC) curves, sensitivity and specificity were calculated. For both methods, associations with low back pain and knee pain were computed using multinomial logistic models. Additional analyses compared older ( $>10$ years) to more recent $(\leq 10$ years $)$ exposures.

Results. AUCs ranged from 0.795 (0.789-0.800) when all periods were considered, to 0.826 (0.820-0.833) for more recent biomechanical exposure ( $\leq 10$ years). Associations between carrying heavy loads and low back pain or knee pain were less strong using JEM assessment than individually SR exposure: for low back pain $\mathrm{OR}_{\mathrm{SR}}=3.02(2.79-3.26)$ vs $\mathrm{OR}_{\mathrm{JEM}}=1.70$ (1.59-1.82) and for knee pain $\mathrm{OR}_{\mathrm{SR}}=2.27(2.10-2.46)$ vs $\mathrm{OR}_{\mathrm{JEM}}=1.64$ (1.53-1.77).

Conclusion. JEM Constances' assessment of cumulative exposure of carrying heavy loads seems to be a useful method compared to a self-administrated questionnaire for large population-based studies where other methods are not available. 
Keywords: job-exposure matrix, self-report, exposure assessment, questionnaire, retrospective, biomechanical, carrying heavy loads, musculoskeletal, epidemiology

Running head: Job-exposure matrix score compared with self-reported carrying of heavy loads 


\section{INTRODUCTION}

Work-related biomechanical exposures are a major determinant of musculoskeletal disorders (MSDs), the most common work-related disorders in terms of frequency and disability. (Bevan, 2015; Descatha et al., 2019a; Hulshof et al., 2019; Roquelaure, 2016). However, assessment of biomechanical exposures remains difficult (Leclerc, 2005). Direct measurements or observations obtained prospectively are considered as the reference, but are unrealistic in large-scale population studies for cost and feasibility reasons (van der Beek and Frings-Dresen, 1998). In such studies, self-reported (SR) assessment is the most commonly used exposure assessment method (Leclerc, 2005). In this context, job-exposure matrices (JEMs) for biomechanical exposures were created (Solovieva et al., 2012; Descatha et al., 2018; Evanoff et al., 2019b) for use where job title is available and not individual exposure data (Jakobsen et al., 2018; Sirén et al., 2019).

We compared a cumulative exposure score based on JEM Constances, an existing biomechanical JEM, to SR exposures of carrying heavy loads in a large French cohort.

\section{METHODS}

\section{Population}

CONSTANCES is a population based multicenter cohort which included, from 2012 to 2018, 162,115 volunteers between 18 to 69 years of age who were randomly selected among people covered by the French National Health Insurance (Goldberg et al., 2017). Data collection included self-administered questionnaires conducted at home and in health screening centers (HSC). 


\section{Variables}

From the baseline questionnaire at the HSC, participants were asked to report whether they carried heavy loads during their working life as 'ever/never'. If 'ever', up to three periods of exposure to heavy loads could be reported with calendar years.

“JEM Constances” was previously developed among 35,526 currently employed workers in the CONSTANCES cohort (Evanoff et al., 2019b). Self-reported exposures from each workers' current job were averaged at the level of 407 job titles (French 4-digit PCS2003 Profession et Catégorie Sociale). To avoid reporting biases due to current symptoms, only data from workers without musculoskeletal symptoms were used. One JEM question addressed carrying heavy loads: "During a typical working day, are you required to regularly handle, move or carry a load, part or object weighing between 10 and 25 kg?” Responses were $0=$ No; if yes $1=[$ Never or nearly never $] 2=[$ Rarely $(<2$ hours per day $)] 3=[$ Often $(2$ to 4 hours per day)] 4= [Always or nearly always]. There was some overlap between the 26,929 subjects who provided SR data on carrying heavy loads (ever/never) and the 26,821 asymptomatic workers whose SR exposures were used in the creation of the JEM; due to sampling procedures of these separate studies we cannot quantify the degree of overlap.

In a questionnaire completed at home, each CONSTANCES participant also completed a job history, listing all jobs and the dates held during their working life. For the current study, the JEM Constances exposure rating (0 to 4 ) for each job held was multiplied by the number of years worked in that job. The summation of these 'lifting-years' products was the cumulative JEM exposure score during each participants' working life, which was subsequently 
compared to the SR data. This JEM exposure score was then compared to each individuals' SR data.

Low back pain and knee pain were the two pain outcomes considered for analysis. Each outcome was measured by three questions: "Pain over the last 12 months(ever/never)”; "Pain duration over the last 12 months(<24 hours, 1-7 days, 8-30 days, >30 days, permanent)”; and "Intensity of pain at the time of the questionnaire(0 to 10 scale)". We defined pain in 3 levels: (i)No pain over the last 12 months; (ii)Moderate pain (non-permanent pain, with intensity of pain $\leq 5$ ); and (iii)“Important” pain (permanent pain or pain intensity >5).

\section{Statistical analysis}

We used Spearman's rank and intraclass correlations to assess the relationship of exposure duration between the two assessment methods. Area Under Curve (AUCs) provided by Receiver Operating Characteristic (ROC) curves were calculated for JEM exposures with the SR exposure (ever/never) as reference. Then the optimal score cut-off was identified as the point on the curve with the highest sensitivity and specificity, and used to dichotomize exposures as 'Not exposed' and 'Exposed', allowing calculation of sensitivity and specificity with their 95\% confidence intervals (95\%CI). Multinomial logistic models computed the odds ratios (ORs) and 95\%CI for associations between each exposure, SR and JEM exposure (Exposed/Not exposed), and each of two outcomes: low back pain and knee pain ('No pain' as reference).

Additional analyses compared potential recall effects for SR and JEM exposures from the recent and more distant past. ROC statistics (AUCs, sensitivity, specificity) and multinomial 
logistic models were performed comparing jobs from $\leq 10$ and $>10$ years ago. All analyses were done on R3.5.1.

\section{RESULTS}

We analyzed 26,929 subjects (53.4\% women) for whom both SR exposure and cumulative lifting-years score based on the JEM were available. The mean age was 48.6 years. Twentysix percent of the sample reported exposure to carrying heavy loads in their working lives; three exposure periods were reported by $0.6 \%$ of the sample $(n=149)$. The computed score of cumulative exposure based on the JEM lifting-years ranged from 0 to 200, with an average of 16.71. Half of the sample suffered from knee pain (37.2\% moderate and $13.6 \%$ "important" pain) while two-thirds complained of low back pain (47.8\% moderate and 19.3\% "important" pain).

Among the exposed subjects, the mean duration of exposure based on the job history and JEM lifting-years score was longer than the duration of SR lifting exposure $(24.9( \pm 11.0)$ vs 14.6( \pm 11.6$)$ years respectively). Exposure durations between the two methods were moderately correlated $\left(\mathrm{rho}_{\text {Spearman }}=0.49\right.$, rho $\left._{\text {intraclass }}=0.43\right)$.

ROC curves and AUCs (Figure 1) showed overall good agreement between the SR and JEM lifting-years score (AUC=0.795). A higher AUC was found for more recent exposures $(\leq 10$ years) compared to older exposures (>10 years) (respectively 0.826 and 0.797 ). Using the optimal cut-off points of 8.07 (all periods), 6.32 (older exposure) and 3.53 (more recent exposure) produced the following sensitivity and specificity values: sensitivityall-periods,

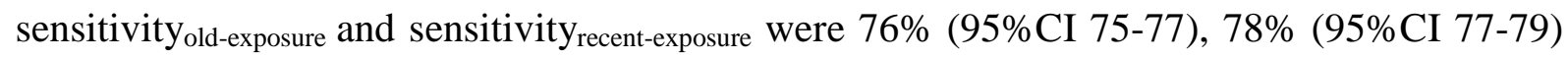
and $\quad 81 \% \quad$ (95\%CI $80-82)$ respectively; specificityall-periods, specificityold-exposure and 
specificityrecent-exposure were of 71\% (95\%CI 70-71), 68\% (95\%CI 68-69) and 73\% (95\%CI 7273) respectively.

The multinomial logistic regression models of low back pain and knee pain associated with exposures assessed by SR and JEM Constances are presented in Table 1. For both 'all periods' and 'subgroup periods', SR exposure to carrying heavy loads showed statistically significant associations with low back pain and knee pain. Associations were stronger for “important” pain than with moderate pain. Models using JEM-based exposures to pain outcomes showed similar findings but smaller effect sizes.

\section{DISCUSSION}

Exposure to heavy lifting and carrying obtained from JEM Constances showed general agreement and produced similar exposure-disease associations when compared with individually self-reported exposures to carrying heavy loads. This agreement with individual SR exposures suggests that JEMs for biomechanical exposures are a useful tool for assigning cumulative work exposures when job titles and job histories are available. Our statistical approach compared JEM values to SR values using AUC, sensitivity and specificity in a similar fashion to previous studies examining the usefulness of general population JEMs for biomechanical exposures (Solovieva et al., 2012).

Our study has some limitations. JEM Constances was developed using pooled self-reported exposures within a different sample of the CONSTANCES cohort participants (Evanoff et al., 2019b) than that used in this study, though it is likely that there is overlap between the two 
samples. The SR and JEM exposure questions were different, as were the methods of assessing years of exposure (time period based vs. job based), likely resulting in some of the differences between the two methods. The moderate correlation of time of exposure illustrated that the methods are different, as expected (Barrero et al., 2009). The fact that the SR data were limited to three jobs periods while the JEM included all periods, including those with relatively low exposure levels, could also explain differences. While SR exposures have shown low validity when compared to direct measurements in some studies (Balogh et al., 2004; Hansson et al., 2001), they may represent an alternative to more resource-intensive and invasive exposure biomechanical assessment methods (Buchholz et al., 2008) in large epidemiological studies, where average SR at the group level appear reasonably correct (Pulido et al., 2017), especially for handling loads over 5 kg (Wiktorin et al., 1993). Moderate to high correlations were previously observed between JEM Constances and a different JEM based on expert opinion (Descatha et al., 2018, 2019b; Evanoff et al., 2019a).

JEM Constances was developed from current work exposures reported at study inception; the cumulative work exposure does not account for potential temporal variations in exposures since the JEM assigned the same value to all years (1950-2018) in the same job title.

These results showing associations between Constances JEM exposures and “important” pain confirmed previous studies showing the usefulness of JEMs based partially or entirely on SR for studying musculoskeletal disorders (Dale et al., 2018; Jakobsen et al., 2018; Sirén et al., 2019). The difference in strength of association seen in our study between the two exposure methods can be interpreted differently. Unlike SR, JEM exposures do not account for individual variation of exposures within the same job (Bouyer and Hémon, 1993) and so may underestimate the true relationship between exposure and symptomatic disorders. Alternatively, by providing an estimate of past exposure unbiased by disease status, JEM 
exposures may avoid overestimation of exposure associated with recall bias when using individual self-reported exposures, and thus provide a better estimate of true associations (Viikari-Juntura et al., 1996).

In conclusion, JEM Constances’ assessment of cumulative exposure of carrying heavy loads found similar results to those obtained using a self-administrated questionnaire in a large population-based survey. Use of JEM for estimating biomechanical exposures in large population studies seems to be a useful epidemiological tool when other exposure data are not feasible, or when control for biased recall of exposures is desired. The utility and limitations of such JEMs are an active area of current research. 
Funding This study was supported by IReSP, CapaciT project (Institute for research in public health, in French- http://www.iresp.net/). The Constances Cohort Study was supported and funded by the Caisse nationale d'assurance maladie (CNAM). The Constances Cohort Study is an "Infrastructure nationale en Biologie et Santé" and benefits from a grant from ANR (ANR-11-INBS-0002) and from the Ministry of Research. Constances is also partly funded by MSD, AstraZeneca and Lundbeck by Inserm-Transfert.

Conflict of interest None declared. Authors are paid by their institutions. Alexis Descatha is also paid as Editor-in-chief by Elsevier Masson.

Ethics All participants signed informed consent. The protocol of the CONSTANCES study (http://www.constances.fr/) was approved by the Comité consultatif pour le traitement des informations relatives à la santé (CCTIRS) and the Commission Nationale de l'Informatique et Liberté (CNIL). 


\section{REFERENCES}

Balogh, I., Ørbaek, P., Ohlsson, K., Nordander, C., Unge, J., Winkel, J., Hansson, G.-A., and Malmö Shoulder/Neck Study Group (2004). Self-assessed and directly measured occupational physical activities--influence of musculoskeletal complaints, age and gender. Appl Ergon 35, 49-56.

Barrero, L.H., Katz, J.N., Perry, M.J., Krishnan, R., Ware, J.H., and Dennerlein, J.T. (2009). Work pattern causes bias in self-reported activity duration: a randomised study of mechanisms and implications for exposure assessment and epidemiology. Occup Environ Med 66, 38-44.

van der Beek, A.J., and Frings-Dresen, M.H. (1998). Assessment of mechanical exposure in ergonomic epidemiology. Occup Environ Med 55, 291-299.

Bevan, S. (2015). Economic impact of musculoskeletal disorders (MSDs) on work in Europe. Best Pract Res Clin Rheumatol 29, 356-373.

Bouyer, J., and Hémon, D. (1993). Retrospective evaluation of occupational exposures in populationbased case-control studies: general overview with special attention to job exposure matrices. Int $\mathrm{J}$ Epidemiol 22 Suppl 2, S57-64.

Buchholz, B., Park, J.-S., Gold, J.E., and Punnett, L. (2008). Subjective ratings of upper extremity exposures: inter-method agreement with direct measurement of exposures. Ergonomics 51, 10641077.

Dale, A.M., Ekenga, C.C., Buckner-Petty, S., Merlino, L., Thiese, M.S., Bao, S., Meyers, A.R., Harris-Adamson, C., Kapellusch, J., Eisen, E.A., et al. (2018). Incident CTS in a large pooled cohort study: associations obtained by a Job Exposure Matrix versus associations obtained from observed exposures. Occup Environ Med 75, 501-506.

Descatha, A., Despréaux, T., Petit, A., Bodin, J., Andersen, J.H., Dale, A.-M., Evanoff, B.A., and Roquelaure, Y. (2018). [Development of "MADE", a French Job exposure matrix for evaluation of biomechanical exposure]. Sante Publique 30, 333-337.

Descatha, A., Evanoff, B.A., Leclerc, A., and Roquelaure, Y. (2019a). Occupational Determinants of Musculoskeletal Disorders. In Handbook of Disability, Work and Health, U. Bültmann, and J. Siegrist, eds. (Cham: Springer International Publishing), pp. 1-20.

Descatha, A., Evanoff, B.A., Andersen, J.H., Baca, M., Buckner-Petty, S., Fadel, M., Ngabirano, L., Roquelaure, Y., and Dale, A.M. (2019b). Comparison Between a Self-Reported Job Exposure Matrix (JEM CONSTANCES) to an Expertise-Based Job Exposure Matrix (MADE) for Biomechanical Exposures. J. Occup. Environ. Med. 61, e399-e400.

Evanoff, B., Yung, M., Buckner-Petty, S., Baca, M., Andersen, J.H., Roquelaure, Y., Descatha, A., and Dale, A.M. (2019a). Cross-national comparison of two general population job exposure matrices for physical work exposures. Occup Environ Med.

Evanoff, B.A., Yung, M., Buckner-Petty, S., Andersen, J.H., Roquelaure, Y., Descatha, A., and Dale, A.M. (2019b). The CONSTANCES job exposure matrix based on self-reported exposure to physical risk factors: development and evaluation. Occup Environ Med. 
Goldberg, M., Carton, M., Descatha, A., Leclerc, A., Roquelaure, Y., Santin, G., Zins, M., and CONSTANCES team (2017). CONSTANCES: a general prospective population-based cohort for occupational and environmental epidemiology: cohort profile. Occup Environ Med 74, 66-71.

Hansson, G.A., Balogh, I., Byström, J.U., Ohlsson, K., Nordander, C., Asterland, P., Sjölander, S., Rylander, L., Winkel, J., Skerfving, S., et al. (2001). Questionnaire versus direct technical measurements in assessing postures and movements of the head, upper back, arms and hands. Scand $\mathrm{J}$ Work Environ Health 27, 30-40.

Hulshof, C.T.J., Colosio, C., Daams, J.G., Ivanov, I.D., Prakash, K.C., Kuijer, P.P.F.M., Leppink, N., Mandic-Rajcevic, S., Masci, F., van der Molen, H.F., et al. (2019). WHO/ILO work-related burden of disease and injury: Protocol for systematic reviews of exposure to occupational ergonomic risk factors and of the effect of exposure to occupational ergonomic risk factors on osteoarthritis of hip or knee and selected other musculoskeletal diseases. Environ Int 125, 554-566.

Jakobsen, E.L.T., Biering, K., Kærgaard, A., Dalbøge, A., and Andersen, J.H. (2018). Long-term prognosis for neck-shoulder pain and disorders: a 14-year follow-up study. Occup Environ Med 75, 90-97.

Leclerc, A. (2005). Exposure assessment in ergonomic epidemiology: is there something specific to the assessment of biomechanical exposures? Occup Environ Med 62, 143-144.

Pulido, J.A., Barrero, L.H., Mathiassen, S.E., and Dennerlein, J.T. (2017). Correctness of SelfReported Task Durations: A Systematic Review. Ann Work Expo Health 62, 1-16.

Roquelaure, Y. (2016). Promoting a Shared Representation of Workers' Activities to Improve Integrated Prevention of Work-Related Musculoskeletal Disorders. Saf Health Work 7, 171-174.

Sirén, M., Viikari-Juntura, E., Arokoski, J., and Solovieva, S. (2019). Physical and psychosocial work exposures as risk factors for disability retirement due to a shoulder lesion. Occup Environ Med 76, 793-800.

Solovieva, S., Pehkonen, I., Kausto, J., Miranda, H., Shiri, R., Kauppinen, T., Heliövaara, M., Burdorf, A., Husgafvel-Pursiainen, K., and Viikari-Juntura, E. (2012). Development and validation of a job exposure matrix for physical risk factors in low back pain. PLoS ONE 7, e48680.

Viikari-Juntura, E., Rauas, S., Martikainen, R., Kuosma, E., Riihimäki, H., Takala, E.P., and Saarenmaa, K. (1996). Validity of self-reported physical work load in epidemiologic studies on musculoskeletal disorders. Scand J Work Environ Health 22, 251-259.

Wiktorin, C., Karlqvist, L., and Winkel, J. (1993). Validity of self-reported exposures to work postures and manual materials handling. Stockholm MUSIC I Study Group. Scand J Work Environ Health 19, 208-214. 


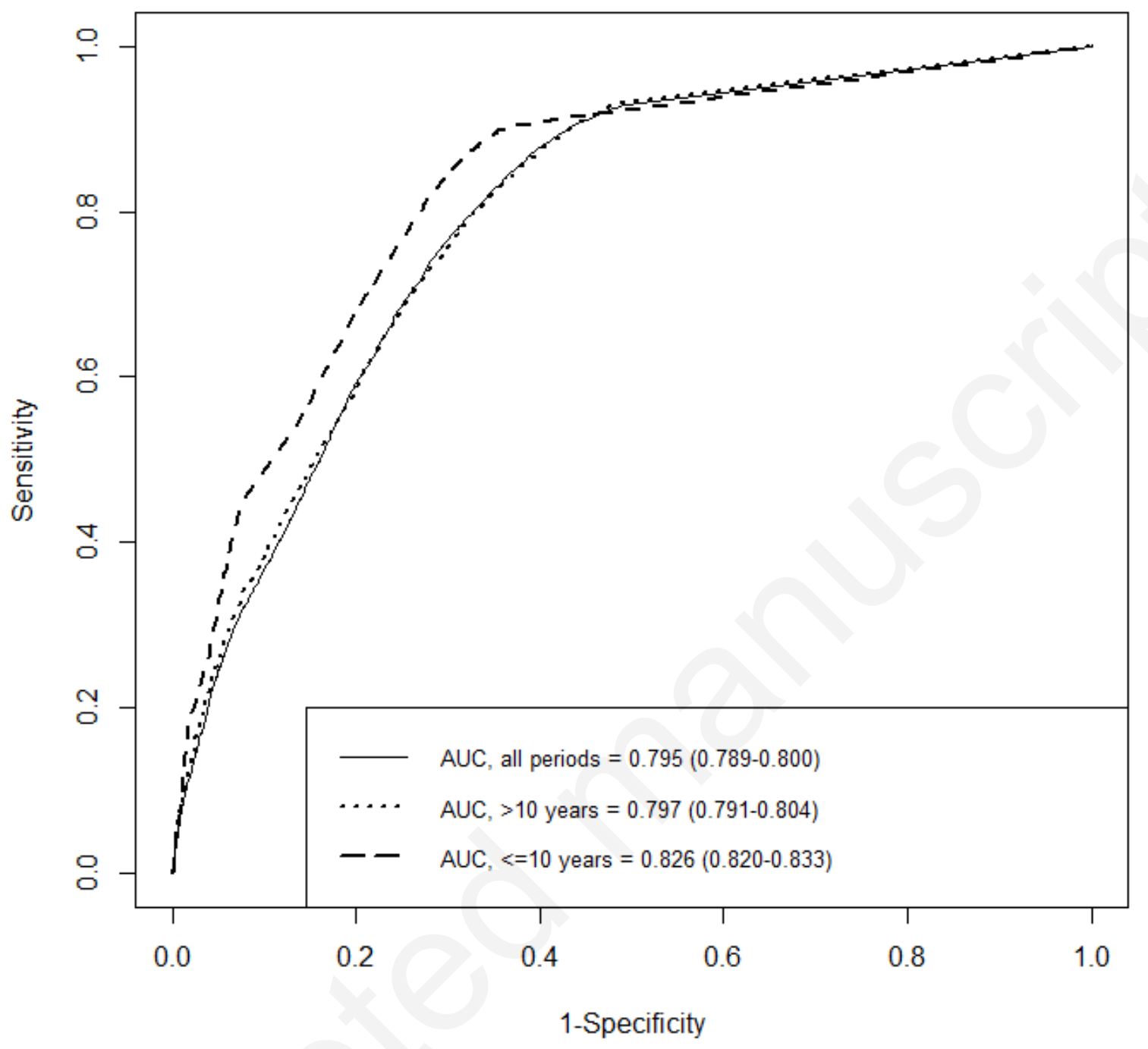

Figure 1: ROC curves for carrying heavy loads $(10-25 \mathrm{~kg})$ 
Table 1: Odds ratios (95\% confidence intervals) for low back pain and knee pain by assessment method

\begin{tabular}{|c|c|c|c|c|c|c|}
\hline & \multicolumn{2}{|c|}{$\begin{array}{l}\text { All periods } \\
(\mathrm{n}=26,929)\end{array}$} & \multicolumn{2}{|c|}{$\begin{array}{c}\text { Older exposure (> 10 years) } \\
(\mathrm{n}=21,534)\end{array}$} & \multicolumn{2}{|c|}{$\begin{array}{l}\text { More recent exposure ( } \leq 10 y e a r s) \\
\qquad(n=22,673)\end{array}$} \\
\hline & $\begin{array}{c}\text { Self-reported } \\
(\mathrm{n} \text { exposed }=7,066)\end{array}$ & $\begin{array}{l}\text { JEM Constances } \\
(\mathrm{n} \text { exposed }=11,213)^{\mathrm{x}}\end{array}$ & $\begin{array}{c}\text { Self-reported } \\
(\mathrm{n} \text { exposed }=5,171)\end{array}$ & $\begin{array}{l}\text { JEM Constances } \\
{\text { (n exposed }=9,208)^{x}}^{\text {J }}\end{array}$ & $\begin{array}{c}\text { Self-reported } \\
\text { ( } \mathrm{n} \text { exposed }=4,784)\end{array}$ & $\begin{array}{l}\text { JEM Constances } \\
(n \text { exposed }=8,767)^{\mathrm{x}}\end{array}$ \\
\hline $\begin{array}{l}\text { Low back pain } \\
\text { No pain=reference }\end{array}$ & & & & & & \\
\hline Moderate pain & $1.66(1.55-1.78)$ & $1.13(1.07-1.20)$ & 1.57 (1.45-1.69) & $1.08(1.01-1.14)$ & $1.76(1.62-1.90)$ & $1.18(1.12-1.25)$ \\
\hline Important pain & $3.02(2.79-3.26)$ & $1.70(1.59-1.82)$ & $2.96(2.71-3.23)$ & $1.58(1.47-1.70)$ & $3.17(2.89-3.48)$ & $1.73(1.60-1.86)$ \\
\hline $\begin{array}{l}\text { Knee pain } \\
\text { No pain=reference }\end{array}$ & & & & & & \\
\hline Moderate pain & $1.36(1.28-1.44)$ & $1.04(0.98-1.09)$ & $1.35(1.26-1.45)$ & $1.04(0.98-1.10)$ & $1.40(1.31-1.51)$ & $1.07(1.01-1.13)$ \\
\hline Important pain & $2.27(2.10-2.46)$ & $1.64(1.53-1.77)$ & $2.33(2.13-2.54)$ & 1.56 (1.45-1.69) & $2.25(2.05-2.47)$ & $1.56(1.45-1.69)$ \\
\hline
\end{tabular}

$\mathrm{x}$ : Number of subjects exposed after dichotomization using the cut-off chosen by the maximum point on the ROCs. 